\title{
Hydrodeoxygenation of phenolic model compounds over zirconia supported Ir and Ni-catalysts
}

\author{
Moldir Alda-Onggar ${ }^{1}$. Päivi Mäki-Arvela ${ }^{1} \cdot$ Atte Aho $^{1}$ - Irina L. Simakova ${ }^{2}$. \\ Dmitry Yu. Murzin ${ }^{1}$
}

Received: 10 September 2018 / Accepted: 15 November 2018 / Published online: 22 November 2018

(c) The Author(s) 2018

\begin{abstract}
The hydrodeoxygenation (HDO) of three different phenolic model compounds, isoeugenol, guaiacol and vanillin was investigated using $\mathrm{Ir} / \mathrm{ZrO}_{2}$ and $\mathrm{Ni} / \mathrm{ZrO}_{2}$ as heterogeneous catalysts. The catalysts were prepared by incipient wetness impregnation and characterized by transmission electron microscopy, nitrogen adsorption, FTIR pyridine adsorption-desorption. The organic material in the spent catalysts was analyzed by organic elemental analysis and thermogravimetry. The results revealed that in guaiacol $\mathrm{HDO}$ at $250{ }^{\circ} \mathrm{C}$ under 30 bar total pressure the main product was cyclohexanol with $36 \%$ yield over $\mathrm{Ni} / \mathrm{ZrO}_{2}$ while the total deoxygenation forming cyclohexane was limited to $2 \%$. $\mathrm{Ir} / \mathrm{ZrO}_{2}$ exhibited higher $\mathrm{HDO}$ activity compared to $\mathrm{Ni} / \mathrm{ZrO}_{2}$ giving $14 \%$ yield of cyclohexane. Extensive formation of methane and ethane was also observed in guaiacol HDO. Hydrodeoxygenation of isoeugenol over $\mathrm{Ir} / \mathrm{ZrO}_{2}$ resulted in maximally $33 \%$ yield of propylcyclohexane due to a low liquid phase mass balance. The main products in vanillin $\mathrm{HDO}$ at $100{ }^{\circ} \mathrm{C}$ in water was vanillyl alcohol.
\end{abstract}

Keywords Hydrodeoxygenation · Phenolic compounds · Heterogeneous catalyst · Nickel · Iridium

Electronic supplementary material The online version of this article (https://doi.org/10.1007/s1114 4-018-1502-1) contains supplementary material, which is available to authorized users.

Päivi Mäki-Arvela

pmakiarv@abo.fi

1 Johan Gadolin Process Chemistry Centre, Åbo Akademi University, Turku, Finland

2 Boreskov Institute of Catalysis, Novosibirsk, Russia 


\section{Introduction}

The hydrodeoxygenation of lignin derived bio-oils is currently an important research area due to depleting fossil fuel resources. Bio-oils as such are not suitable as fuels due to high acidity, oxygen content and instability [1]. There exist already some publications from the HDO of bio-oils [2, 3], but due to complicated analytics, several model compounds have been very often used including guaiacol [4], vanillin [5, 6], isoeugenol [7], anisole [8], phenol [9, 10] and cresol [11]. The use of model compounds also facilitates easier elucidation of the reaction mechanism [9]. Several attempts has also been made to elucidate the potential industrial application of the HDO of phenolic compounds, e.g. performing HDO of their mixtures in the absence of any other solvents [12]. One example of this type of experiments was HDO of the vanillin-guaiacol mixture at $200{ }^{\circ} \mathrm{C}$ under 30 bar hydrogen [12]. Only vanillin gave large amounts of partially deoxygenated product, $p$-creosol, under these conditions, whereas guaiacol did not produce any deoxygenated products. This result showed clearly some challenges in up-scaling HDO since different phenolic compounds are adsorbed on the surface with different strength depending on their structure and a number of oxygen atoms.

Several catalysts have been applied, e.g. metals (Pt, Pt-Sn, Pd, Ru) supported on carbon [5], zeolites [7], carbides [6] and oxides [8]. Bifunctional catalysts, containing both metal and acidic functionality have also been used [7]. The aim in this work was to make a comparative HDO study of three phenolic compounds, namely vanillin, guaiacol and isoeugenol (Fig. 1) using zirconia supported metals, nickel and iridium as catalysts. It is known that zirconia based catalysts exhibit oxophilic sites promoting adsorption of oxygenated compounds. For example $\mathrm{Ni} / \mathrm{ZrO}_{2}$ was successfully used as a catalyst in continuous hydrodeoxygenation of $\mathrm{m}$-cresol in dodecane under 40 bar total pressure in hydrogen at $340{ }^{\circ} \mathrm{C}$ giving as the main products deoxygenated methylcyclohexane and methylcyclohexenes [13]. On the other hand, nearly twofold more oxygenates were formed over $\mathrm{Ni} / \mathrm{SiO}_{2}$ under the same conditions showing the importance of the support.

The HDO of guaiacol, eugenol and vanillin has been already demonstrated over metal supported $\mathrm{ZrO}_{2}$ (Table 1) [4, 14, 15]. HDO of guaiacol was reported to be the most successful over $\mathrm{Ni} / \mathrm{SiO}_{2}-\mathrm{ZrO}_{2}$ giving $97 \%$ yield of methylcyclohexane at $300{ }^{\circ} \mathrm{C}$ and 50 bar catalyst in $8 \mathrm{~h} \mathrm{[15].} \mathrm{The} \mathrm{second} \mathrm{best} \mathrm{catalyst} \mathrm{was} 10 \mathrm{wt} \%$ $\mathrm{Ni} / \mathrm{ZrO}_{2}$ catalyst giving $75 \%$ selectivity of cyclohexane at $44 \%$ of conversion of guaiacol (entries 2 and 3). On the other hand, $5 \mathrm{wt} \% \mathrm{Ni} / \mathrm{ZrO}_{2}$ resulted in $30 \%$ yield of cyclohexane at complete guaiacol conversion (entry 3). Furthermore, the calcined and reduced $5 \mathrm{wt} \% \mathrm{Ni} / \mathrm{ZrO}_{2}$ resulted in higher cyclohexane selectivity $(30 \%)$ than the non-treated catalyst directly used giving only $1 \%$ of cyclohexane. This result indicates that calcination is very important to activate the catalyst and enhance hydrodeoxygenation. The $\mathrm{HDO}$ activities of $3 \mathrm{wt} \% \mathrm{Rh} / \mathrm{ZrO}_{2}$ and $5 \mathrm{wt} \%$ $\mathrm{Ru} / \mathrm{ZrO}_{2}$ were not very high with these catalysts producing mainly hydrogenated products such as 2-methoxycyclohexanol (89\% and 36\%) and cyclohexanol 
(5 and 36\%) [16]. Bimetallic catalysts supported on zirconium oxide exhibited high yields of alcohols but no deoxygenated compounds (entry 7). Summarizing guaiacol HDO, it can be stated that in order to achieve high selectivity to hydrodeoxygenated compounds, a high hydrogen pressure and a relatively high temperature are required, especially with $\mathrm{Ni} / \mathrm{ZrO}_{2}$ [15]. Eugenol hydrodeoxygenation was demonstrated over $\mathrm{Co} / \mathrm{ZrO}_{2}$ at $200{ }^{\circ} \mathrm{C}$ under 10 bar hydrogen in dodecane as a solvent [14] giving propylcyclohexanol as the main product with $57 \%$ yield at complete conversion. $\mathrm{Co} / \mathrm{ZrO}_{2}$ exhibited strong acidity determined by ammonia TPD.

As a comparison to guaiacol $\mathrm{HDO}$ over $\mathrm{Ni} / \mathrm{SiO}_{2}-\mathrm{ZrO}_{2}$, vanillin was not converted completely $(83 \%)$ in $8 \mathrm{~h}$ at $300{ }^{\circ} \mathrm{C}$ and 50 bar in a mixture of cresol, phenol, eugenol, trans-anethole and vanillin [4]. The main product was methylcyclohexane with $65 \%$ selectivity at $83 \%$ conversion [4], showing that vanillin is more difficult to deoxygenate in comparison to other phenolic compounds present in the mixture for which complete conversion was obtained. Selectivity to propylcyclohexane was $98 \%$ at $300{ }^{\circ} \mathrm{C}$ under 50 bar in $8 \mathrm{~h}$ [4] indicating that zirconia support is beneficial in HDO which can be related to both acidic and basic sites available in zirconia.

Typically, vanillin HDO has been performed in water [5, 6], and as a comparison to our previous vanillin HDO over metal supported on carbon [5], water was also used in this work as a solvent in vanillin HDO. In the previous study with $\mathrm{Pd} / \mathrm{C}$ at $100{ }^{\circ} \mathrm{C}$ under 30 bar total pressure in hydrogen [5] the main product was p-creosol.

The aim in this work was to investigate the potential of oxophilic $\mathrm{ZrO}_{2}$ to be used as a support for metal in HDO of phenolic compounds. According to our knowledge $\mathrm{Ni} / \mathrm{ZrO}_{2}$ and $\mathrm{Ir} / \mathrm{ZrO}_{2}$ have not been used as catalysts in vanillin HDO in water and in isoeugenol HDO. Nickel is a cheap transition metal, whereas Ir in comparison with Pt exhibits hydrogenolysis activity [20] and a homogeneous Ir catalyst was successfully used in the hydrodeoxygenation of 2,5-hexadione [21]. Thus it was decided to use $\mathrm{Ir} / \mathrm{ZrO}_{2}$ as a catalyst in this work. One of the main aims was also to study the liquid phase mass balance closure, since in several papers [14, 22, 23], in addition to reactant conversion the product selectivity has been defined as the ratio between the products formed not reflecting the carbon balance in liquid phase. The mass balance closure, however, can only be found in a very few papers [7, 24-27]. The experiments in this study were performed using a low initial concentration of reactants, which, however, facilitated to directly compare the performance of $\mathrm{ZrO}_{2}$ supported catalysts $\left(\mathrm{Pt} / \mathrm{C}, \mathrm{Pd} / \mathrm{C}, \mathrm{Pt} / \mathrm{H}-\mathrm{Beta}-300, \mathrm{Ir}-\mathrm{Re} / \mathrm{Al}_{2} \mathrm{O}_{3}\right.$, with other ones applied under the same conditions $[5,7,12,26]$. 
(a)<smiles>COC1CCCCC1=O</smiles>

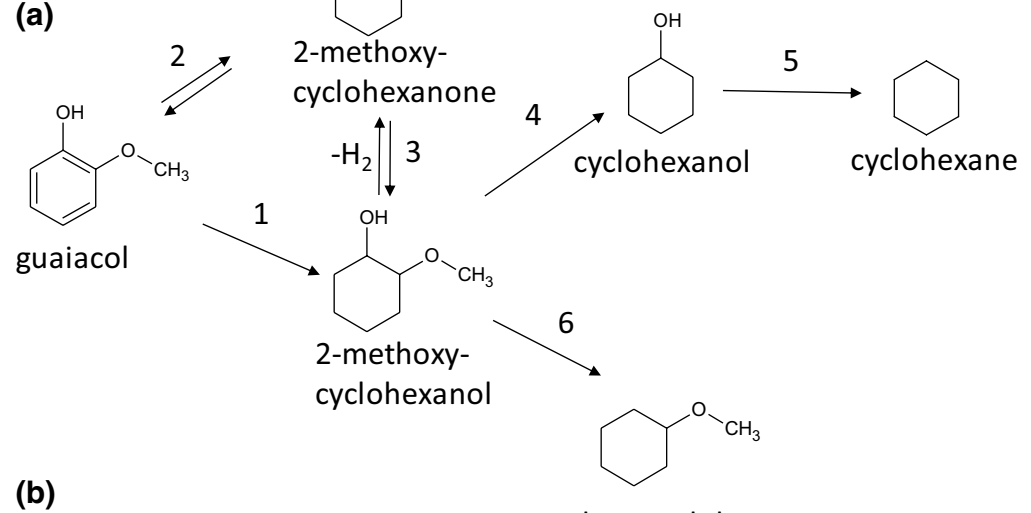

(b)

methoxycyclohexane<smiles>COc1cc(C=O)ccc1O</smiles>

vanillin<smiles>COc1cc(CO)ccc1O</smiles>

vanillyl alcohol<smiles>COc1cc(C)ccc1O</smiles>

p-creosol

(c)<smiles>C/C=C/c1ccc(O)c(OC)c1</smiles><smiles>CCCc1ccc(O)c(OC)c1</smiles><smiles>CCCc1ccccc1</smiles><smiles>CC</smiles><smiles>CCCC1CCCCC1</smiles>

Isoeugenol

dihydroeugenol

propylbenzene

propylcyclohexane<smiles>Cc1ccc(C)c(C)c1</smiles>

trimethylbenzene

Fig. 1 Reaction schemes for HDO of a guaiacol, $\mathbf{b}$ vanillin and $\mathbf{c}$ isoeugenol. Notation: the trivial names for the compounds in vanillin HDO are vanillin (4-hydroxy-3-methoxybenzaldehyde), vanillyl alcohol (4-hydroxy-3-methoxybenzyl alcohol) and p-creosol (2-methoxy-4-methylphenol) 


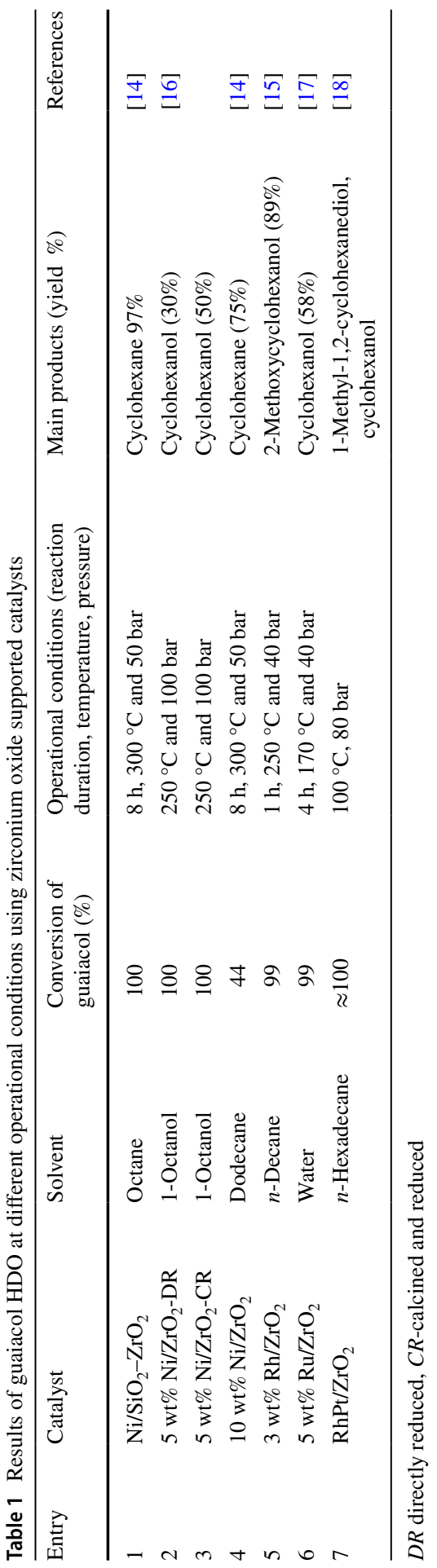




\section{Experimental}

\section{Preparation of catalysts}

All starting materials were reagent grade chemicals such as $\mathrm{Ni}\left(\mathrm{NO}_{3}\right)_{2} \cdot 6 \mathrm{H}_{2} \mathrm{O}$ ( $\geq 98.0 \%$, GOST 405570, Souzchimprom, Novosibirsk), $\mathrm{IrCl}_{3}$ hydrate (TU 2625067-00196533-2002 OAO "V.N. Gulidov Krasnoyarsk factory of nonferrous metals, Krasnoyarsk)", zirconia (Acros Organics, $\mathrm{S}_{\mathrm{BET}}=106 \mathrm{~m}^{2} / \mathrm{g}$ ).

Zirconia was precalcined in air at $500{ }^{\circ} \mathrm{C}$ for $2 \mathrm{~h}$ before catalysts preparation. $3 \mathrm{wt} \% \mathrm{Ir} / \mathrm{ZrO}_{2}$ was prepared by incipient wetness impregnation with an aqueous solution of $\mathrm{IrCl}_{3}$ hydrate, sequentially dried at $110{ }^{\circ} \mathrm{C}$ for $17 \mathrm{~h}$ and reduced by molecular hydrogen from room temperature up to $400{ }^{\circ} \mathrm{C}$ with a ramp rate of $2{ }^{\circ} \mathrm{C} /$ min, thereafter holding in hydrogen during $3 \mathrm{~h}$ to remove the excess of chloride.

$10 \mathrm{wt} \% \mathrm{Ni} / \mathrm{ZrO}_{2}$ was prepared by incipient wetness impregnation with an aqueous solution of a nickel nitrate precursor, sequentially dried at $110^{\circ} \mathrm{C}$ for $17 \mathrm{~h}$, calcined in air at $540{ }^{\circ} \mathrm{C}$ for $2 \mathrm{~h}$ and reduced by molecular hydrogen from room temperature up to $450{ }^{\circ} \mathrm{C}$ with a ramp rate of $2{ }^{\circ} \mathrm{C} / \mathrm{min}$, thereafter holding in hydrogen during $3 \mathrm{~h}$. The reduction temperature, $450{ }^{\circ} \mathrm{C}$ should be enough to reduce $\mathrm{NiO}$ [28].

\section{Catalyst characterization methods}

\section{Nitrogen adsorption}

Specific surface area of the catalysts were determined using nitrogen adsorption at $77 \mathrm{~K}$ using Carlo Erba Sorptomatic 1900. BET program was applied to identify the specific surface area and pore volume of the alumina supported catalysts. The investigated catalysts were heated at $150{ }^{\circ} \mathrm{C}$ and outgassed at a pressure lower than $8 \mathrm{mbar}$ for $3 \mathrm{~h}$.

\section{Acidity measurement with pyridine adsorption desorption by FTIR}

FTIR spectroscopy ATI Mattson with pyridine (Sigma-Aldrich, $\geq 99.5 \%$, a.r.) adsorption desorption was used to determine the amount and strength of Brønsted and Lewis acid sites. Initially, a sample of the catalyst was pressed into a thin pellet with the weight in the range between 10 and $20 \mathrm{mg}$. The prepared pellet was placed in the cell of the spectrometer for $1 \mathrm{~h}$ outgassing in vacuum at $450{ }^{\circ} \mathrm{C}$. Afterwards, the sample was cooled down to the set temperature of $100{ }^{\circ} \mathrm{C}$, followed by adsorption of pyridine on the pellet surface for $30 \mathrm{~min}$ and then recording the scanned spectra. Subsequently, to obtain the acidity strength distribution such as presence of weak, medium and strong Brønsted and Lewis acid sites, the thermal desorption of pyridine was performed at $250{ }^{\circ} \mathrm{C}, 350{ }^{\circ} \mathrm{C}$ and $450{ }^{\circ} \mathrm{C}$. The spectral bands integrated at $1455 \mathrm{~cm}^{-1}$ and $1545 \mathrm{~cm}^{-1}$ provided the data on the Brønsted and Lewis acid sites concentrations using extinction coefficients of Emeis [29]. 


\section{Scanning electron microscopy and X-ray microanalysis (SEM-EDX)}

The scanning electron microscopy coupled with energy dispersive X-ray analyzer was utilized to obtain information on the morphology and elemental analysis of the fresh and spent catalysts. Zeiss Leo Gemini 1530 microscope combined with secondary electron and backscattered electron detectors was applied for this purpose. Acceleration voltage of $15 \mathrm{kV}$ was used for X-ray analyzer. In order to perform analysis, the catalyst was placed as a thin layer on top of the carbon coating to enhance the conductivity allowing high quality of magnified images.

\section{Transmission electron microscopy (TEM)}

Transmission electron microscopy was utilized to study the morphology and metal particle size. The equipment used for analysis was JEM-1400Plus (by JEOL Ltd. Japan) of $120 \mathrm{kV}$ maximal acceleration voltage. The interpretation of TEM images and determination of the particles sizes of the fresh and spent catalysts were done using ImageJ program.

\section{Thermogravimetric analysis (TGA)}

Thermogravimetric characterization of the fresh and spent catalysts was carried out using SDT Q600 (V20.9 Build 20) device under nitrogen. Around $7 \mathrm{mg}$ of the catalyst was placed on an aluminum oxide $\left(\mathrm{Al}_{2} \mathrm{O}_{3}\right)$ sample pan as well as an empty pan on the reference and heated from room temperature to $1000{ }^{\circ} \mathrm{C}$ (temperature ramp$10{ }^{\circ} \mathrm{C} / \mathrm{min}$ ). The volumetric gas flow rate during analysis was $100 \mathrm{ml} / \mathrm{min}$. The organic compounds and coke adsorbed on the catalyst surface have been calculated from the difference between the spent and fresh catalyst weight losses in the temperature range of $100-1000{ }^{\circ} \mathrm{C}$, i.e. not considering the amount of water desorbed.

\section{Catalytic experiments}

HDO of isoeugenol and guaiacol was performed in an autoclave with the initial concentrations of $0.012 \mathrm{~mol} / \mathrm{l}$ and $0.016 \mathrm{~mol} / \mathrm{l}$, respectively using $50 \mathrm{ml}$ of dodecane (Alfa Aesar, $\geq 99 \%$ ) as a solvent. In a typical experiment $50 \mathrm{mg}$ of the prereduced catalyst was put into the reactor together with the reactant. 1 day prior to HDO of isoeugenol and guaiacol, the fresh catalysts were reduced with hydrogen (AGA, 99.999\%). First, $50 \mathrm{mg}$ of the catalyst was flushed with argon flow for $10 \mathrm{~min}$ and then with hydrogen for $10 \mathrm{~min}$. The program was set to heat up from room temperature to $350{ }^{\circ} \mathrm{C}$ with $10{ }^{\circ} \mathrm{C} / \mathrm{min}$ and keep at $350{ }^{\circ} \mathrm{C}$ for $3 \mathrm{~h}$ under hydrogen flow. Afterwards, as the program was completed and temperature decreased to $100{ }^{\circ} \mathrm{C}$, the catalyst was flushed with argon (AGA, 99.999\%) for $10 \mathrm{~min}$ and $10 \mathrm{ml}$ of the solvent (dodecane) was added onto the catalyst and kept overnight.

The reactor was flushed with argon (Ar, 99.999\%) for 10 min followed by flushing with hydrogen for $5 \mathrm{~min}$ and pressurizing to 20 bar with hydrogen (AGA, $99.999 \%$ ) at room temperature. Thereafter, the temperature was increased to the 
desired one and the final pressure was adjusted to 30 bar total pressure. The reaction was commenced by starting the stirring. The external and internal mass transfer limitations were suppressed by using a high stirring speed (900 rpm) and small catalyst particles below $63 \mu \mathrm{m}$. The samples were taken from the reactor after certain time intervals and analyzed by GC. The gas sample was taken at the end of the reaction.

For vanillin $\mathrm{HDO}$, the experiments were performed in an autoclave using $100 \mathrm{ml}$ distilled water as a solvent. In a typical experiment vanillin initial concentration was $0.008 \mathrm{~mol} / \mathrm{l}$ and $50 \mathrm{mg}$ of the pre-reduced catalyst was used. The catalyst was covered with distilled water after reduction in Ar atmosphere prior to the experiment.

\section{Gas chromatography for the liquid phase samples}

Analysis of the samples in the HDO of guaiacol and isoeugenol was performed by a gas chromatograph using DB-1 capillary column (Agilent 122-103e) of $30 \mathrm{~m}$ length, $250 \mu \mathrm{m}$ internal diameter and $0.5 \mu \mathrm{m}$ film thickness was utilized for GC analysis. Helium (AGA, 99.996\%) was applied as a carrier gas with flowrate of $1.7 \mathrm{ml} / \mathrm{min}$. The temperature program for $\mathrm{GC}$ analysis is $60{ }^{\circ} \mathrm{C}(5 \mathrm{~min})-3{ }^{\circ} \mathrm{C} /$ min-135 ${ }^{\circ} \mathrm{C}-15^{\circ} \mathrm{C} / \mathrm{min}-300{ }^{\circ} \mathrm{C}$. The following external calibration standards for HDO of isoeugenol and guaiacol: isoeugenol (cis and trans) (Fluka, >98\%), guaiacol (Aldrich, $\geq 98 \%$ ), dihydroeugenol (Sigma-Aldrich, $\geq 99 \%$ ), cyclohexane (Lab Scan, 99\%), heptane (Sigma-Aldrich, $\geq 99 \%$ ), 2,5-dimethylhexane (Sigma-Aldrich, 99\%), octane (Fluka, $\geq 99 \%$ ), propylcyclohexane (Aldrich, 99\%), 2-methoxycyclohexanone (TCI,>95\%), methoxycyclohexane (TCI,>98\%) were utilized for quantitative determination.

For the gas phase samples in the HDO of guaiacol, $1 \mathrm{ml}$ of gas sample was taken from the reactor and analyzed with an Agilent $6890 \mathrm{~N}-\mathrm{GC}$ equipped with HP-PLOTQ capillary column $(30 \mathrm{~m} \times 530 \mu \mathrm{m} \times 40 \mu \mathrm{m})$. The pressure and temperature were respectively 1.03 bar and $250{ }^{\circ} \mathrm{C}$ and the total gas flow was $55.2 \mathrm{ml} / \mathrm{min}$ (with the split ratio of 5:1). Detection was done by FID $\left(300{ }^{\circ} \mathrm{C}\right)$ and $\operatorname{TCD}\left(250{ }^{\circ} \mathrm{C}\right)$. The mixtures of calibration gases from AGA contained carbon dioxide (1 V \%), ethylene $(0.099 \mathrm{~V} \%)$, methane $(1.02 \mathrm{~V} \%)$, and methane $(1 \mathrm{~V} \%)$, ethane $(1.03 \mathrm{~V} \%)$, propane $(0.981 \mathrm{~V} \%)$, isobutene $(0.983 \mathrm{~V} \%)$, n-butane $(0.96 \mathrm{~V} \%)$ in helium.

Gas chromatography/mass spectrometry (Agilent Technologies 122-103e) was used to identify both gas and liquid phase compounds. DB-1 capillary column (Agilent $122-103 \mathrm{e}$ ) of $30 \mathrm{~m}$ length, $250 \mu \mathrm{m}$ internal diameter and $0.5 \mu$. $\mathrm{m}$ film thickness was utilized for GC analysis. Helium (AGA, 99.996\%) was applied as a carrier gas with the flowrate of $1.7 \mathrm{ml} / \mathrm{min}$. The temperature program for separation of the liquid phase compounds was $60{ }^{\circ} \mathrm{C}(5 \mathrm{~min})-3{ }^{\circ} \mathrm{C} / \mathrm{min}-135{ }^{\circ} \mathrm{C}-15^{\circ} \mathrm{C} / \mathrm{min}-300{ }^{\circ} \mathrm{C}$. The program applied for the gas phase samples was 40 or $60{ }^{\circ} \mathrm{C}(5 \mathrm{~min}) 3{ }^{\circ} \mathrm{C} / \mathrm{min}-135^{\circ} \mathrm{C}-15^{\circ} \mathrm{C} /$ $\min -300{ }^{\circ} \mathrm{C}$.

High performance liquid chromatography was applied for the analysis of samples obtained from HDO of vanillin. HPLC (Agilent Technologies 1100 Series) was supplied with a UV-vis photo diode array detector $(273 \mathrm{~nm})$ and a qternary pump. The utilized column was Ultra Techsphere ODS-5u (C18) $(250 \mathrm{~mm} \times 4.6 \mathrm{~mm})$. The 
non-stationary phase was a mixture of methanol and $0.5 \%$ phosphoric acid with the flowrate of $0.400 \mathrm{ml} / \mathrm{min}$. The program set for the flow of the mixture (methanol $+0.5 \%$ phosphoric acid) using a gradient for the eluent given in Table S1. External calibration curves were made for vanillin and vanillyl alcohol.

\section{Definitions}

To assess the yield of the liquid phase products, gas chromatography based sum of the reactants and products in the liquid phase analysis (GCLPA) was calculated as follows:

$$
G C L P A=\frac{G C L P A_{t}}{G C L P A_{0}} \times 100 \% .
$$

Here GCLPA $_{0}$ is the initial gas chromatography based sum of the reactants and products in the liquid phase analysis; GCLPA $_{t}$ is the gas chromatography based sum of the reactants and products in the liquid phase analysis at time $t$.

At a constant volume, conversion of the reactant was calculated in a conventional way using the following equation:

$$
X_{a, t}=\frac{C_{0}-C_{i}}{C_{0}} \times 100 \% .
$$

Here $\mathrm{X}_{\mathrm{a}, \mathrm{t}}$ is the conversion of a particular reactant at time $\mathrm{t}, \% ; \mathrm{C}_{\mathrm{a}, 0}$ is the initial molar concentration of the reactant, $\mathrm{mol} / \mathrm{l} ; \mathrm{C}_{\mathrm{a}, \mathrm{t}}$ is the molar concentration of the reactant at time $\mathrm{t}, \mathrm{mol} / \mathrm{l}$. The conversion of dihydroeugenol has been defined as its maximum concentration minus concentration of dihydroeugenol at time $t$ divided by the maximum dihydroeugenol concentration, multiplied by $100 \%$.

\section{Results and discussion}

\section{Catalyst characterization results}

The morphology of the catalysts was investigated by scanning electron microscopy and transmission electron microscopy. The SEM images (Fig. 2) did not show big differences in the shapes between fresh $3 \mathrm{wt} \% \mathrm{Ir} / \mathrm{ZrO}_{2}$ and $10 \mathrm{wt} \% \mathrm{Ni} /$ $\mathrm{ZrO}_{2}$, except the size range. For $\mathrm{Ir} / \mathrm{ZrO}_{2} 24 \mu \mathrm{m}$ to $122 \mu \mathrm{m}$ while for $10 \mathrm{wt} \% \mathrm{Ni} /$ $\mathrm{ZrO}_{2}$ this interval was somewhat larger (10-160 $\left.\mu \mathrm{m}\right)$.

A possible metal leaching was excluded by comparing the mass ratio of $\mathrm{Ir} / \mathrm{Zr}$ and $\mathrm{Ni} / \mathrm{Zr}$ in the fresh and spent catalysts used in $\mathrm{HDO}$ of isoeugenol at $250{ }^{\circ} \mathrm{C}$ under 30 bar total pressure in hydrogen. For $3 \mathrm{wt} \% \mathrm{Ir} / \mathrm{ZrO}_{2}$ and $10 \mathrm{wt} \% \mathrm{Ni} / \mathrm{ZrO}_{2}$ no changes in the mass ratio of metal to $\mathrm{Zr}$ were observed by SEM-EDX. The Ir/ $\mathrm{Zr}$ and $\mathrm{Ni} / \mathrm{Zr}$ mass ratios were 0.1 and 0.2 , respectively both in fresh and spent catalysts indicating no significant leaching in the spent catalysts. 
(a)

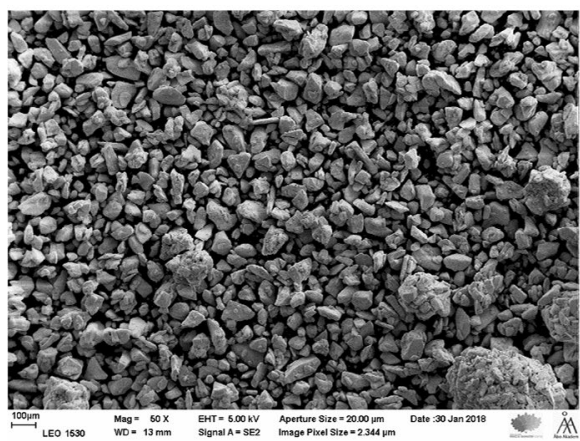

(b)

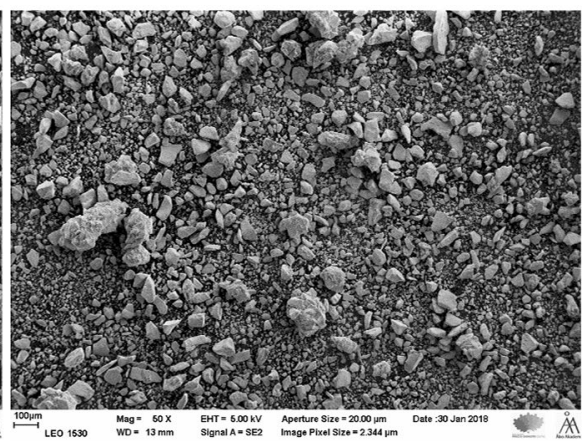

Fig. 2 SEM images for the fresh catalysts (magnification $\times 100$ ). $\mathbf{a} \mathrm{Ir} / \mathrm{ZrO}_{2}$, b $10 \mathrm{wt} \% \mathrm{Ni} / \mathrm{ZrO}_{2}$

Based on $3 \mathrm{wt} \% \mathrm{Ir} / \mathrm{ZrO}_{2}$ images, the particle size in the fresh and spent catalysts is $1.3 \mathrm{~nm}$ and $2.2 \mathrm{~nm}$. From $10 \mathrm{wt} \% \mathrm{Ni} / \mathrm{ZrO}_{2}$ catalyst images it was not possible to differentiate nickel and zirconia support.

TEM image for the reduced, fresh $10 \mathrm{wt} \% \mathrm{Ni} / \mathrm{ZrO}_{2}$ contained large nickel nanoparticles are covered by nickel oxide thin layer and decorated by smaller nanocrystals of zirconia (Fig. 3a). Ni particle sizes varied in the range of 20 to $50 \mathrm{~nm}$ in diameter and separate nickel particles bigger than $100 \mathrm{~nm}$ could also be found. High iridium dispersion in the fresh $3 \mathrm{wt} \% \mathrm{Ir} / \mathrm{ZrO}_{2}$ catalyst can be seen in the TEM image (Fig. 3b, Table 2). Although the spent catalyst exhibited also a high metal dispersion, some agglomerates were present, varying from $4 \mathrm{~nm}$ to $14 \mathrm{~nm}$ (Fig. 3c).

The specific surface area for the impregnated $10 \mathrm{wt} \% \mathrm{Ni} / \mathrm{ZrO}_{2}$ used in the current work was $108 \mathrm{~m}^{2} / \mathrm{g}$ while its pore volume was very low (Table 2). On the other hand, $3 \mathrm{wt} \% \mathrm{Ir} / \mathrm{ZrO}_{2}$ catalyst contained a high pore volume in comparison with $10 \mathrm{wt} \% \mathrm{Ni} / \mathrm{ZrO}_{2}$. According to Zhang et al. [15], $10 \mathrm{wt} \% \mathrm{Ni} / \mathrm{ZrO}_{2}$ synthesized by deposition-precipitation had a specific surface area of only $6.2 \mathrm{~m}^{2} / \mathrm{g}$. According to [17], $5 \mathrm{wt} \% \mathrm{Ni} / \mathrm{ZrO}_{2}$ prepared by incipient wetness impregnation had specific surface area of $130 \mathrm{~m}^{2} / \mathrm{g}$. Therefore, the catalysts made by impregnation method have larger specific surface area $\left(>100 \mathrm{~m}^{2} / \mathrm{g}\right)$, while, deposition precipitation results in lower specific surface area.

Both $3 \mathrm{wt} \% \mathrm{Ir} / \mathrm{ZrO}_{2}$ and $10 \mathrm{wt} \% \mathrm{Ni} / \mathrm{ZrO}_{2}$ exhibit mainly weak Lewis acid sites (Table 3). In addition $10 \mathrm{wt} \% \mathrm{Ni} / \mathrm{ZrO}_{2}$ exhibits also large amounts of Brønsted acidity, which is in accordance with literature [30] showing that the ratio of Brønsted to Lewis acidity determined by pyridine adsorption DRIFTs for $20 \mathrm{wt} \% \mathrm{Ni} / \mathrm{ZrO}_{2}$ was 7.6 fold higher than for $20 \mathrm{wt} \% \mathrm{Ni} / \mathrm{SiO}_{2}$. Brønsted acidity in $10 \mathrm{wt} \% \mathrm{Ni} / \mathrm{ZrO}_{2}$ catalyst is originating from $\mathrm{HNO}_{3}$ which was used to dissolve the Ni precursor and the $\mathrm{pH}$ of the precursor solution was between 1 and 2 . After $2 \mathrm{~h}, \mathrm{NiO}$ was formed on $\mathrm{ZrO}_{2}$. It is known that $\mathrm{Zr}^{4+}$ present in $\mathrm{ZrO}_{2}$ exhibits also Lewis acidity [31]. Furthermore, it is expected that part of $\mathrm{Ni}$ can be as $\mathrm{Ni}^{2+}$ on the surface of $\mathrm{Ni} / \mathrm{ZrO}_{2}$ since the concentration of Lewis acid sites was increasing 2.5 fold compared to that of Ir/ $\mathrm{ZrO}_{2}$. It is reasonable to suggest that a large amount of $\mathrm{Ni}$ is more difficult to reduce completely in comparison with Ir. 
(a)

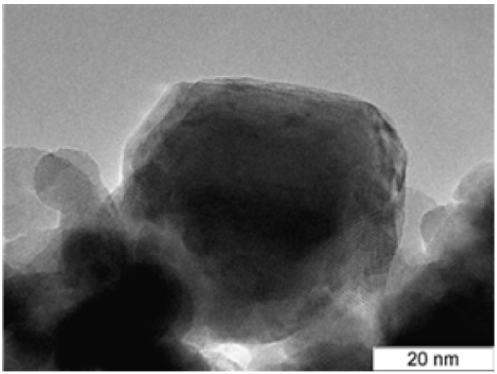

(b)
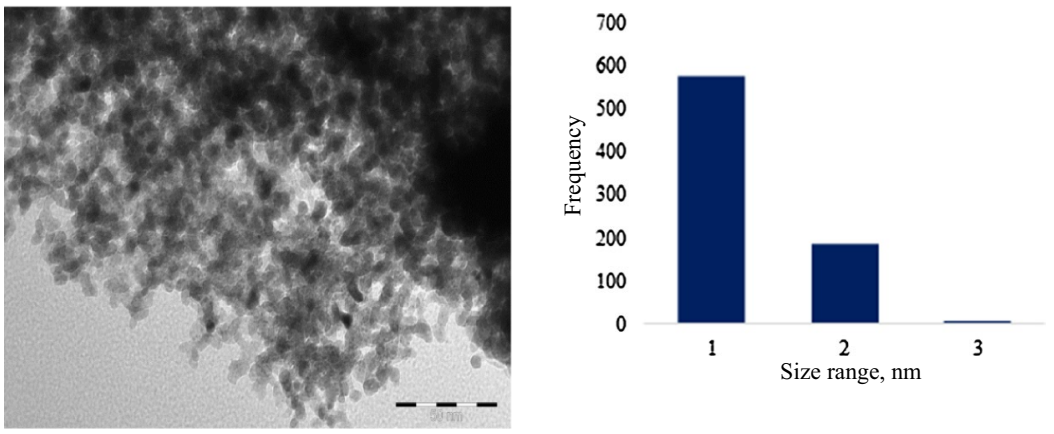

(c)
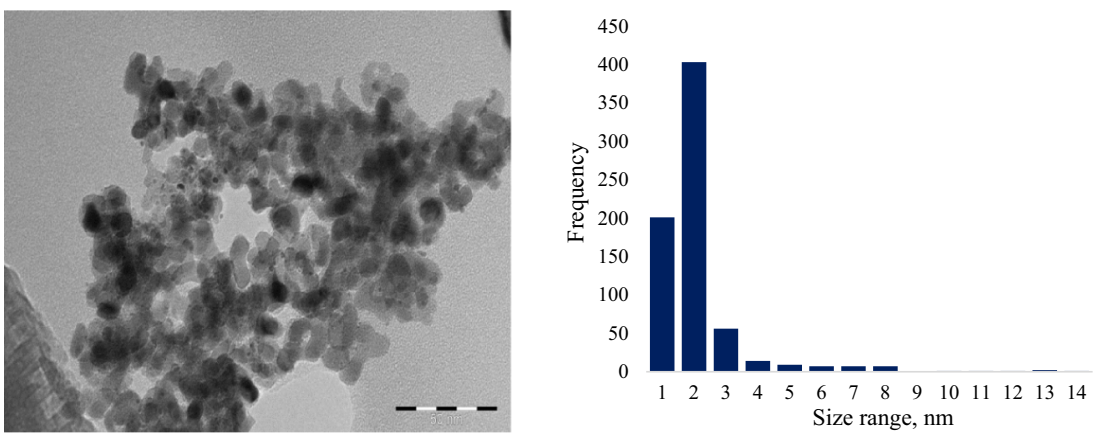

Fig. 3 TEM images and histograms of the metal particle sizes for $\mathbf{a}$ the fresh $10 \mathrm{wt} \% \mathrm{Ni} / \mathrm{ZrO}_{2}$ and $\mathbf{b}$ fresh and c spent $3 \mathrm{wt} \% \mathrm{Ir} / \mathrm{ZrO}_{2}$ catalyst used in isoeugenol $\mathrm{HDO}$ at $250{ }^{\circ} \mathrm{C}$ and 30 bar total pressure

Table 2 Catalyst characterization data

\begin{tabular}{lllll}
\hline Catalyst & $\begin{array}{l}\text { Specific surface area } \\
\left(\mathrm{m}^{2} / \mathrm{g}_{\mathrm{cat}}\right)\end{array}$ & $\begin{array}{l}\text { Pore volume } \\
\left(\mathrm{cm}^{3} / \mathrm{g}\right)\end{array}$ & $\begin{array}{l}\text { Calculated disper- } \\
\text { sion }(\%)\end{array}$ & $\begin{array}{l}\text { Metal particle } \\
\text { size, TEM } \\
(\mathrm{nm})^{\mathrm{a}}\end{array}$ \\
\hline $10 \mathrm{wt} \% \mathrm{Ni} / \mathrm{ZrO}_{2}$ & 108 & 0.04 & n.d. & $1.1,20-50^{\mathrm{b}}$ \\
$3 \mathrm{wt} \% \mathrm{Ir} / \mathrm{ZrO}_{2}$ & 91 & 0.24 & $77(45)$ & $1.3(2.2)$ \\
\hline
\end{tabular}

${ }^{\mathrm{a}}$ In parenthesis value for the spent catalyst

${ }^{\mathrm{b}}$ Some particles also above $100 \mathrm{~nm}$ 
Table 3 Brønsted and Lewis acid sites determined by FTIR

\begin{tabular}{llllllll}
\hline Catalyst & \multicolumn{2}{l}{ Brønsted acid sites $\left(\mu \mathrm{mol} / \mathrm{g}_{\text {cat }}\right)$} & & \multicolumn{3}{l}{ Lewis acid sites $\left(\mu \mathrm{mol} / \mathrm{g}_{\text {cat }}\right)$} \\
\cline { 2 - 4 } \cline { 6 - 8 } & $250{ }^{\circ} \mathrm{C}$ & $350{ }^{\circ} \mathrm{C}$ & $450{ }^{\circ} \mathrm{C}$ & & $250{ }^{\circ} \mathrm{C}$ & $350{ }^{\circ} \mathrm{C}$ & $450{ }^{\circ} \mathrm{C}$ \\
\hline $3 \mathrm{wt} \% \mathrm{Ir}-\mathrm{ZrO}_{2}$ & 1 & 0 & 0 & & 157 & 0 & 0 \\
$10 \mathrm{wt} \% \mathrm{Ni}-\mathrm{ZrO}_{2}$ & 70 & 0 & 0 & & 398 & 1 & 0 \\
\hline
\end{tabular}

Table 4 Organic coking results based on data via TGA

\begin{tabular}{ll}
\hline Catalyst & $\begin{array}{l}\text { Organic coke in } \\
\text { nitrogen, }(\%)\end{array}$ \\
\hline $3 \mathrm{wt} \% \mathrm{Ir} / \mathrm{ZrO}_{2}$ & $3.5^{\mathrm{a}}$ \\
$10 \mathrm{wt} \% \mathrm{Ni} / \mathrm{ZrO}_{2}$ & $2.9^{\mathrm{a}}$ \\
$3 \mathrm{wt} \% \mathrm{Ir} / \mathrm{ZrO}_{2}$ & $5.1^{\mathrm{b}}$ \\
$10 \mathrm{wt} \% \mathrm{Ni} / \mathrm{ZrO}_{2}$ & $3.2^{\mathrm{b}}$ \\
\hline
\end{tabular}

${ }^{\mathrm{a}}$ Obtained using corresponding spent catalysts from isoeugenol HDO at $250{ }^{\circ} \mathrm{C}$ and 30 bar

${ }^{\mathrm{b}}$ Obtained using corresponding spent catalysts from guaiacol HDO at $250{ }^{\circ} \mathrm{C}$ and 30 bar

TGA results for the fresh and spent catalysts in the guaiacol and isoeugenol HDO at $250{ }^{\circ} \mathrm{C}$ and 30 bar aluminum oxide and zirconium oxide supported catalysts) show that only small amounts of organic coke was obtained (Table 4), not being able to explain the low amounts of reactant and products analyzed by GC.

\section{HDO results}

\section{Isoeugenol HDO}

HDO of isoeugenol was investigated at $150{ }^{\circ} \mathrm{C}, 200{ }^{\circ} \mathrm{C}$ and $250{ }^{\circ} \mathrm{C}$ for $4 \mathrm{~h}$ both with $10 \mathrm{wt} \% \mathrm{Ni} / \mathrm{ZrO}_{2}$ and $3 \mathrm{wt} \% \mathrm{Ir} / \mathrm{ZrO}_{2}$ catalysts (Table 5, Figs. 4 and 5). The hydrogenation of isoeugenol to dihydroeugenol was very rapid already during heating as confirmed earlier [26, 32]. The transformation rate of isoeugenol after $1 \mathrm{~min}$ was, however very slow over $\mathrm{Ni} / \mathrm{ZrO}_{2}$ (Fig. 4a) indicating catalyst deactivation, which was confirmed by coking, since the spent catalyst contained carbon according to TGA results (Table 4). Conversion of dihydroeugenol over $10 \mathrm{wt} \% \mathrm{Ni} / \mathrm{ZrO}_{2}$ increased with increasing temperature (Table 5). Complete conversion of isoeugenol was already achieved during heating the reactor at $250{ }^{\circ} \mathrm{C}$. Dihydroeugenol was, however, transformed quite slowly over $\mathrm{Ni} / \mathrm{ZrO}_{2}$ catalysts, about $0.004 \mathrm{~mol} / \mathrm{ming}_{\mathrm{Ni}}$ during 1 to $30 \mathrm{~min}$.

Isoeugenol was converted over $\mathrm{Ir} / \mathrm{ZrO}_{2}$ already at $150{ }^{\circ} \mathrm{C} 82 \%$ after 1 min reaction time and for the two other temperatures, $200{ }^{\circ} \mathrm{C}$ and $250{ }^{\circ} \mathrm{C}$ it was converted even faster and complete conversion of isoeugenol was obtained at all temperatures (Table 5). Dihydroeugenol conversion increased with increasing temperature 


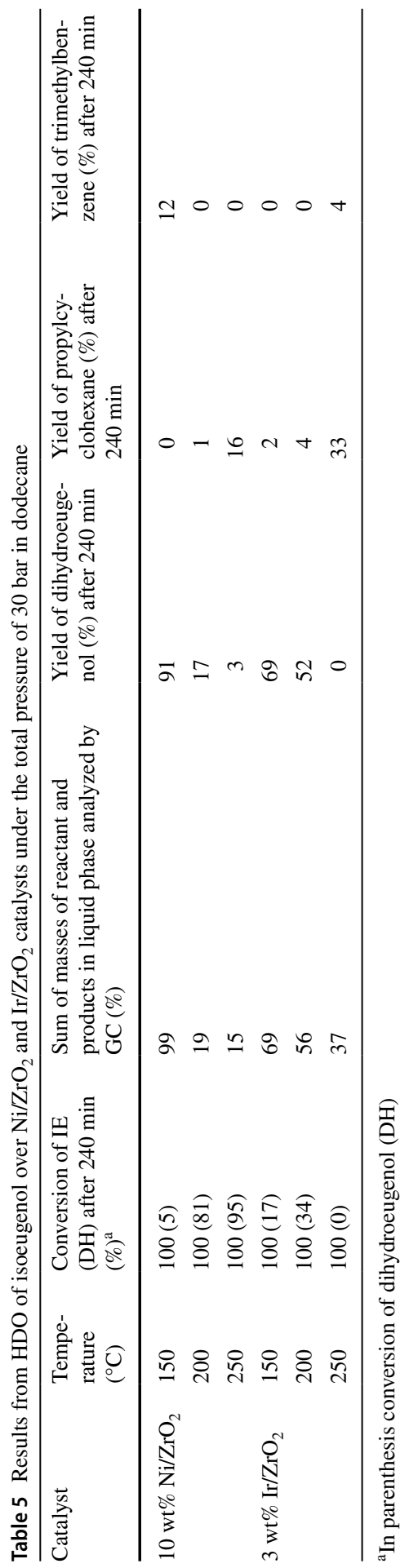



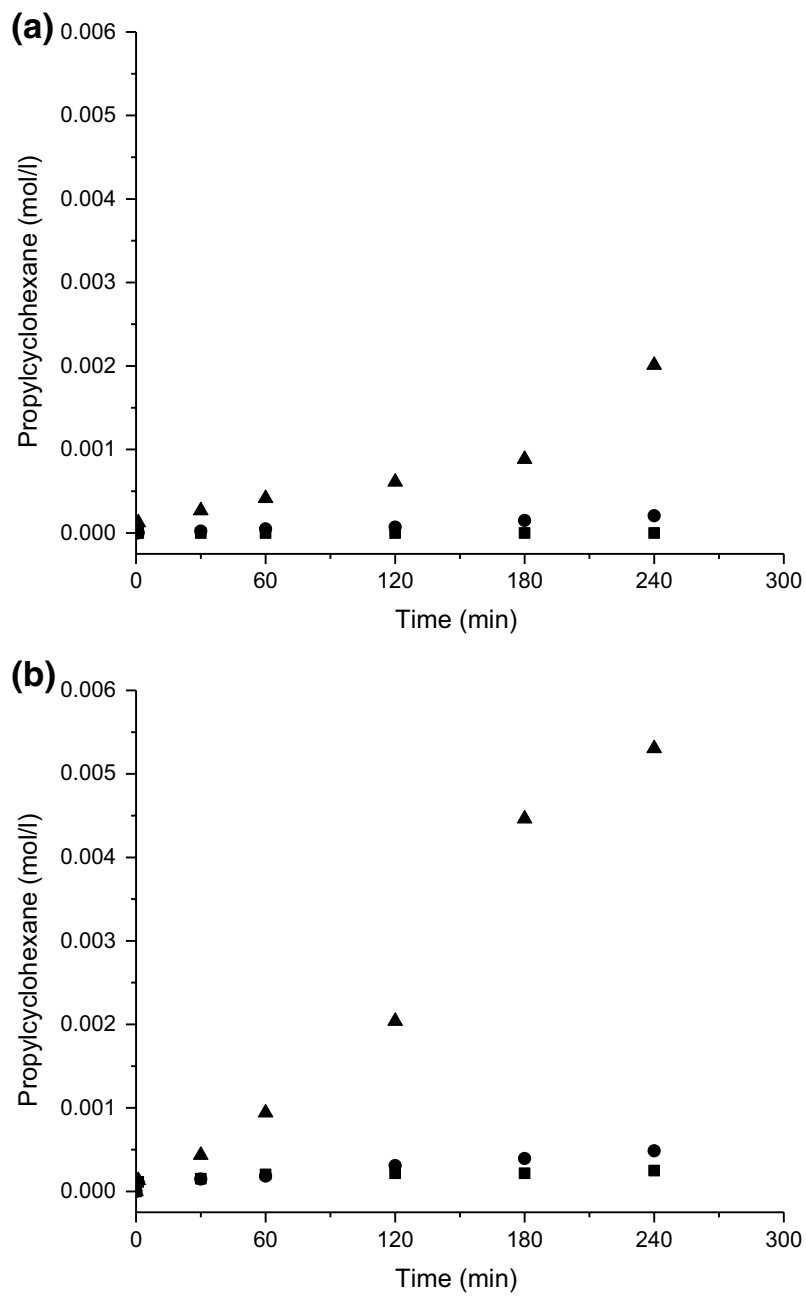

Fig. 4 Kinetics for formation of propylcyclohexane in $\mathrm{HDO}$ of isoeugenol over a $10 \mathrm{wt} \% \mathrm{NiZrO}_{2}$ and $\mathbf{b}$ $3 \mathrm{wt} \% \mathrm{Ir} / \mathrm{ZrO}_{2}$ catalysts. Notation (filled square) $150{ }^{\circ} \mathrm{C}$, (filled circle) $200{ }^{\circ} \mathrm{C}$ and (filled triangle) $250{ }^{\circ} \mathrm{C}$

(Table 5), but the initial transformation rate of dihydroeugenol was, however, rather slow at $250{ }^{\circ} \mathrm{C}$ being $0.002 \mathrm{~mol} / \mathrm{min} / \mathrm{g}_{\text {Ir }}$ and even after $240 \mathrm{~min}$ at $250{ }^{\circ} \mathrm{C}$ not complete conversion of dihydroeugenol was obtained (Table 5). It can be concluded that dihydroeugenol transformed initially 1.8 -fold faster over $\mathrm{Ni} / \mathrm{ZrO}_{2}$ compared to $\mathrm{Ir} /$ $\mathrm{ZrO}_{2}$. This can be related to hydrogenolysis activity of Ir [19] and smaller particle sizes being more prone to deactivation in comparison with $\mathrm{Ni}$.

The GCLPA decreased over both $\mathrm{Ni} / \mathrm{ZrO}_{2}$ and $\mathrm{Ir} / \mathrm{ZrO}_{2}$ catalysts with increasing reaction temperature and increasing conversion being the lowest for $\mathrm{Ni} / \mathrm{ZrO}_{2}$ at $250{ }^{\circ} \mathrm{C}$ (Table 5). The reason for such lower GCLPA obtained by $\mathrm{Ni} / \mathrm{ZrO} 2$ is its high activity for formation of gaseous products. Furthermore, Ir/ZrO $\mathrm{rO}_{2}$ in 

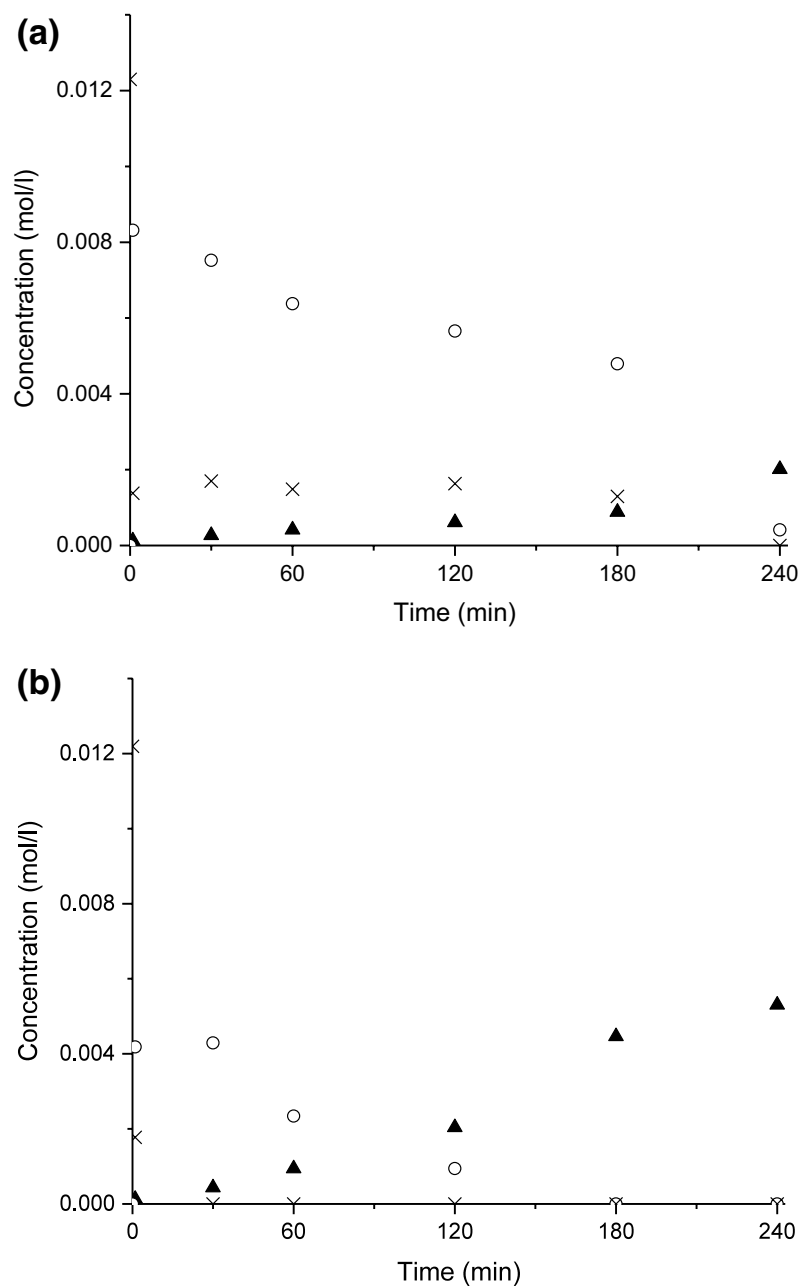

Fig. 5 Kinetics in HDO of isoeugenol over a $\mathrm{NiZrO}_{2}$ and $\mathbf{b} \mathrm{Ir} / \mathrm{ZrO}_{2}$ catalysts. Conditions: $250{ }^{\circ} \mathrm{C}$, total pressure $30 \mathrm{bar}$, initial isoeugenol concentration $0.012 \mathrm{~mol} / \mathrm{l}$, solvent dodecane, catalyst mass $50 \mathrm{mg}$. Notation: isoeugenol (multiplication sign), dihydroeugenol (open circle) and propylcyclohexane (filled triangle)

the current work exhibited only Lewis acidity, whereas $\mathrm{Ni} / \mathrm{ZrO}_{2}$ contained also weak Brønsted acid sites (Table 3). As a comparison Pt supported Beta zeolites containing both Brønsted and Lewis acid sites gave in isoeugenol HDO [7] the GCLPA of $45-61 \%$ at $200{ }^{\circ} \mathrm{C}$ under 30 bar hydrogen. It can be thus concluded that GCLPA with Ir and $\mathrm{Ni}$ supported on $\mathrm{ZrO}_{2}$ was about the same as for Pt-H-Beta catalysts. This comparison indicates that both metal and support selection is very important for obtaining high GCLPAs. Ir is known to be very active in hydrogenolysis [20], while Ni facilitates methanation. Furthermore, the mass balance closure in $\mathrm{HDO}$ of isoeugenol using $\mathrm{Ir}-\mathrm{Re} / \mathrm{Al}_{2} \mathrm{O}_{3}$ was $79 \%$ under comparative 
conditions showing clearly that the selection of support and the amount of iridium are crucial for mass balance closure [26]. The low GCLPA values with the catalysts from this work is due to formation gaseous products [26]. Furthermore, oligomer product formation from isoeugenol in HDO of the latter using Ir-Re/ $\mathrm{Al}_{2} \mathrm{O}_{3}$ catalysts has been previously confirmed via performing extraction of the spent catalyst with heptane and analyzing the extract phase by SEC [26]. Thus the most plausible reasons for a low mass balance closure are formation of oligomers and gaseous products. The results for $\mathrm{Ir} / \mathrm{ZrO}_{2}$ can be also partially explained by large amounts of alkanes such as hexane, heptane and octane formed in the presence of only the solvent, dodecane with $\mathrm{Ir} / \mathrm{ZrO}_{2}$ at $250{ }^{\circ} \mathrm{C}$ and 30 bar total pressure. These compounds have not been taken into account during GCLPA calculations when using isoeugenol as a reactant, because otherwise it leads to GCLPA higher than $100 \%$ in the current experimental setup and it would be impossible to separate formation of alkanes from the solvent and from the reactant. In comparison with literature the mass balance closure in HDO of 4-propylphenol over different Pt supported catalysts under 40 bar hydrogen at $200{ }^{\circ} \mathrm{C}$ in water was $78 \%$ at complete conversion over $\mathrm{Pt} / \mathrm{ZrO}_{2}$, whereas the comparative value with $\mathrm{Pt} / \mathrm{C}$ was $98 \%$ [25] indicating also that zirconia support has a negative effect on the mass balance closure. On the other hand, this result cannot be generalized since reaction conditions, such as high hydrogen pressure, increases the carbon mass balance, as was the case with phenol HDO giving $90 \%$ total mass balance closure under 100 bar at $275^{\circ} \mathrm{C}$ [10].

The yield of the deoxygenated product, propylcyclohexane increased, as expected with increasing temperature for both $\mathrm{ZrO}_{2}$ supported catalysts. It is also interesting to note that only a minor increase in formation rates of propylcyclohexane over $\mathrm{Ir} / \mathrm{ZrO}_{2}$ was observed when increasing the reaction temperature from $150{ }^{\circ} \mathrm{C}$ to $200{ }^{\circ} \mathrm{C}$, whereas at $250{ }^{\circ} \mathrm{C}$ the initial formation rate of propylcyclohexane was 2.9 fold that at $200{ }^{\circ} \mathrm{C}$ (Fig. 4). The initial formation rate for propylcyclohexane over $\mathrm{Ni} / \mathrm{ZrO}_{2}$ at $250{ }^{\circ} \mathrm{C}$ was 11 -fold that calculated at $200{ }^{\circ} \mathrm{C}$ indicating that $\mathrm{Ni} / \mathrm{ZrO}_{2}$ requires higher temperature for $\mathrm{HDO}$ than $\mathrm{Ir} / \mathrm{ZrO}{ }_{2}$. The highest yields for propylcyclohexane were obtained at $250{ }^{\circ} \mathrm{C}$ being $16 \%$ and $33 \%$ for $\mathrm{Ni} / \mathrm{ZrO}_{2}$ and $\mathrm{Ir} / \mathrm{ZrO}_{2}$, respectively, were obtained. These yields are much lower compared to those obtained over Pt-H-Beta-300 and Pt-H-Beta-150 (the number in the catalyst name denotes $\mathrm{SiO}_{2} / \mathrm{Al}_{2} \mathrm{O}_{3}$ ratio) being at $200{ }^{\circ} \mathrm{C} 74 \%$ and $64 \%$ [7] and those reported by Zhang et al. [15]. In [15], 98\% selectivity of propylcyclohexane was obtained at $300{ }^{\circ} \mathrm{C}$ under 50 bar hydrogen in $8 \mathrm{~h}$ using a mixture of eugenol, vanillin, guaiacol, phenol and trans-anethole as a feedstock. In [15] both hydrogen pressure and reaction temperature were much higher than in the current case, most probably enhancing activity of $\mathrm{Ni} / \mathrm{ZrO}_{2}$. Noteworthy is also that formation of 1,2,4-trimethylbenzene was observed over $10 \mathrm{wt} \% \mathrm{Ni} /$ $\mathrm{ZrO}_{2}$ at $150{ }^{\circ} \mathrm{C}$ (Table 5) indicating that despite demethoxylation of the formed dihydroeugenol, hydrogenation of the phenyl ring was, however, not very efficient under these conditions. In addition $\mathrm{C}-\mathrm{C}$ bond breaking in the propyl chain occurred. This result is interesting since e.g. hydrogenation of propylbenzene is thermodynamically feasible at $200{ }^{\circ} \mathrm{C}$ under 30 bar hydrogen [7], but not at $300{ }^{\circ} \mathrm{C}$ under 30 bar. 


\section{Guaiacol HDO}

In the hydrodeoxygenation of guaiacol over $10 \mathrm{wt} \% \mathrm{Ni} / \mathrm{ZrO}_{2}$ at $250{ }^{\circ} \mathrm{C}$ and $30 \mathrm{bar}$ total pressure the initial guaiacol transformation rate between 1 and $30 \mathrm{~min}$ was $1.6 \mathrm{mmol} / \mathrm{min}_{\mathrm{Ni}}$ and complete conversion of guaiacol was obtained after $240 \mathrm{~min}$ (Fig. 5a). GCLPA is rather low being $54 \%$ for $10 \mathrm{wt} \% \mathrm{Ni} / \mathrm{ZrO}_{2}$ (Table 6). To complete the GCLPA, both organic coke and gas phase analysis were performed. Using thermogravimetric analysis, organic coke was estimated from the temperature ramp between 100 and $1000{ }^{\circ} \mathrm{C}$, i.e. excluding water content for both catalysts. GCLPAs increased to 48 and $57 \%$ for $3 \mathrm{wt} \% \mathrm{Ir} / \mathrm{ZrO}_{2}$ and $10 \mathrm{wt} \% \mathrm{Ni} / \mathrm{ZrO}_{2}$, correspondingly, showing that this solid fraction could only slightly increase the GCLPA levels. Thus gas samples were taken after $4 \mathrm{~h}$ of the reaction and analyzed by GC-MS after $4 \mathrm{~h}$ of reaction. Methane was present in the gas phase together with ethane (Table S2, Fig. $\mathrm{S} 3$ ). Methanation is expected to occur via hydrogenation of $\mathrm{CO}$ which is thermodynamically feasible already at $227^{\circ} \mathrm{C}$ at which the Gibbs free energy for methanation is $-96.4 \mathrm{~kJ} / \mathrm{mol}$ [33]. In addition it is known that $\mathrm{Ni}$ is promoting methanation.

Over $\mathrm{Ir} / \mathrm{ZrO}_{2}$ catalyst the initial transformation rate of guaiaocl was $2.1 \mathrm{mmol} /$ mingIr being higher than that for $\mathrm{Ni} / \mathrm{ZrO}_{2}$ and complete conversion of guaiacol was obtained in $4 \mathrm{~h}$ (Table 6). The GCLPA for $\mathrm{Ir} / \mathrm{ZrO}_{2}$ was lower than for $\mathrm{Ni} / \mathrm{ZrO}_{2}$ (Table 6) due to the high hydrogenolysis activity of Ir, as stated above, promoting formation of gaseous products. When comparing the gas phase analysis results (Fig. $\mathrm{S} 3$ ) of $\mathrm{Ir} / \mathrm{ZrO}_{2}$ and $\mathrm{Ni} / \mathrm{ZrO}_{2}$ by GC-MS it can be observed that the distribution of gases for $\mathrm{Ir} / \mathrm{ZrO}_{2}$ catalyst is broader in comparison with $10 \mathrm{wt} \% \mathrm{Ni} / \mathrm{ZrO}_{2}$. Over Ir/ $\mathrm{ZrO}_{2}$ catalyst $\mathrm{CH}_{4}$ gas was produced more than over $10 \mathrm{wt} \% \mathrm{Ni} / \mathrm{ZrO}_{2}$ (retention time of $1.1 \mathrm{~min}$ in Fig. S3). In demethoxylation, the formed alkoxide group can be adsorbed on the metal surface and hydrogenated to form methane and water. Ethane gave the highest peak at the retention time of $1.2 \mathrm{~min}$ for both catalysts (Fig. S3). Formation of more gaseous products over $3 \mathrm{wt} \% \mathrm{Ir} / \mathrm{ZrO}_{2}$ than over $10 \mathrm{wt} \% \mathrm{Ni} / \mathrm{ZrO}_{2}$ could explain lower GCLPA (43\% vs. 54\%).

The main product in guaiacol $\mathrm{HDO}$ over $10 \mathrm{wt} \% \mathrm{Ni} / \mathrm{ZrO}_{2}$ at $250{ }^{\circ} \mathrm{C}$ under $30 \mathrm{bar}$ total pressure was cyclohexanol showing that this catalyst was active in hydrogenation of phenyl ring, but at the same time exhibiting lower HDO activity. In addition, large amounts of 2-methoxycyclohexanone were initially formed. The ratio between the formed cyclohexanol to 2-methoxycyclohexanone at 1 min reaction time was 1.8 indicating that $\mathrm{Ni} / \mathrm{ZrO}_{2}$ catalyst was initially very active in hydrogenation of the phenyl ring and in demethoxylation. 2-methoxycyclohexanone can be formed either via isomerization of 2-methoxycyclohexenol to corresponding ketone or from guaiacol. This result is in accordance with thermodynamics, since it is known that dissociation of methoxy bond requires less energy $(343 \mathrm{~kJ} / \mathrm{mol})$ compared to dissociation of an alcohol group (385 kJ/mol) [34]. $\mathrm{Ni} / \mathrm{ZrO}_{2}$ was, however, able to only partially transform 2-methoxycyclohexanonone to cyclohexane (Fig. 5a) and the yield of fully deoxygenated product, cyclohexane was very low, being only $2 \%$ (Table 6). It can be seen from the kinetic plot that 2-methoxycyclohexanone did not react further since its concentration remained constant. Furthermore cyclohexanol concentration increased during $4 \mathrm{~h}$ reaction, indicating that $10 \mathrm{wt} \% \mathrm{Ni} / \mathrm{ZrO}_{2}$ catalyst mainly containing weak Lewis acid sites (Table 3) was not active in hydrodeoxygenation to 


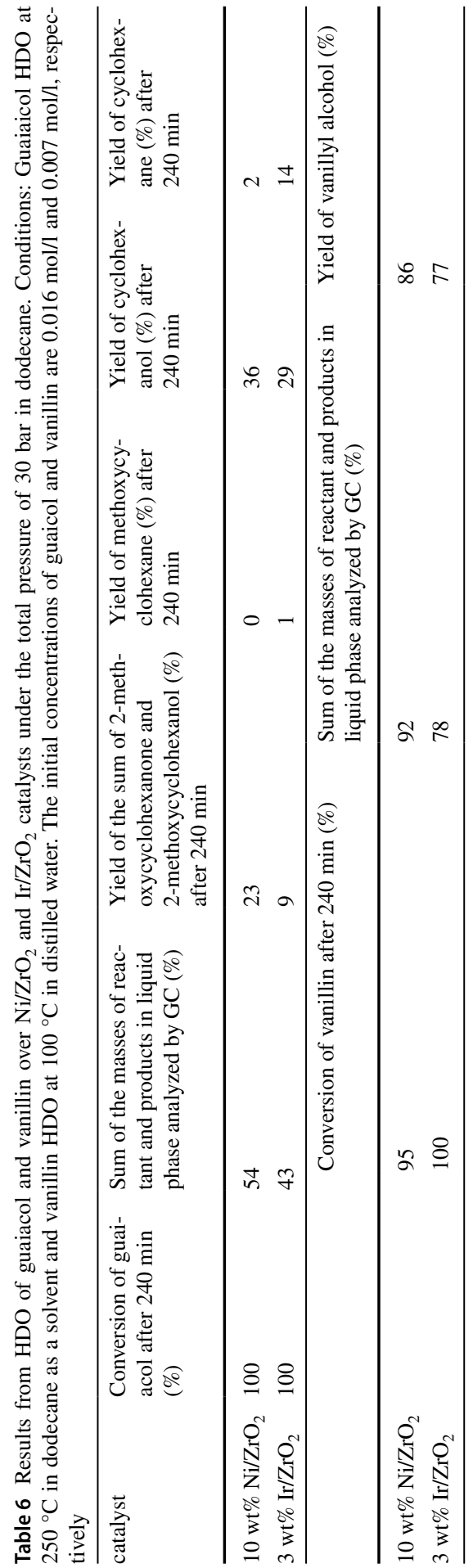




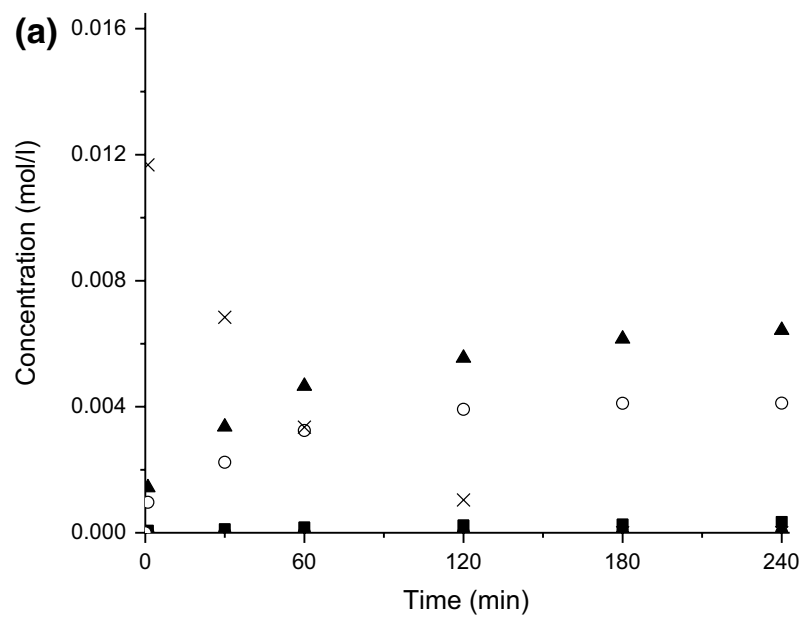

(b)

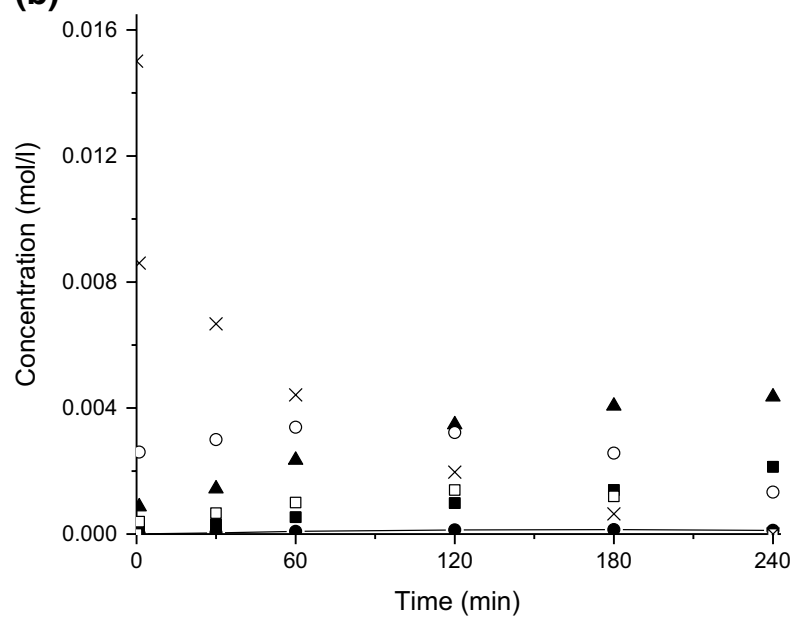

Fig. 6 Kinetics in $\mathrm{HDO}$ of guaiacol over a $\mathrm{Ni} / \mathrm{ZrO} \mathrm{O}_{2}$ and $\mathbf{b} \mathrm{Ir} / \mathrm{ZrO}_{2}$ catalysts. Conditions: $250{ }^{\circ} \mathrm{C}$, total pressure $30 \mathrm{bar}$, initial guaiacol concentration $0.016 \mathrm{~mol} / 1$, solvent dodecane, catalyst mass $50 \mathrm{mg}$. Notation: guaiacol (multiplication sign), methoxycyclohexane (filled circle), 2-methoxy-cyclohexanone (open circle), 2-methoxycyclohexanol (open square), cyclohexanol (filled triangle) and cyclohexane (filled square)

cyclohexane. As comparison with the literature [10], $5 \mathrm{wt} \% \mathrm{Ni} / \mathrm{ZrO}_{2}$ was reported to be very efficient in hydrodeoxygenation of phenol at $275^{\circ} \mathrm{C}$ under 100 bar yielding $80 \mathrm{~mol} \%$ of cyclohexane and $10 \mathrm{~mol} \%$ cyclohexanol. Furthermore, high selectivity towards cyclohexane, $75 \%$ was obtained over $\mathrm{Ni} / \mathrm{ZrO}_{2}$ at $43 \%$ conversion [15]. The conditions in their work [14] were, however, very much more severe compared to the current work.

The main product in guaiacol HDO over $3 \mathrm{wt} \% \mathrm{Ir} / \mathrm{ZrO}_{2}$ was also cyclohexanol (Table 6). Initially 2-methoxycyclohexanone was the main product and its concentration started to decrease after 120 min reaction time (Fig. 6b). The second major 
product already in the beginning of the reaction was cyclohexanol and its concentration increased during $4 \mathrm{~h}$ reaction time. This compound reacted further to cyclohexane, and its concentration was increasing during the reaction. The initial ratio between the yield of cyclohexanol to 2-methoxycyclohexanone was 0.4 showing that $\mathrm{Ni} / \mathrm{ZrO}_{2}$ was initially 4.5-fold more active in transforming 2-methoxycyclohexanone to cyclohexanol than $\mathrm{Ir} / \mathrm{ZrO}_{2}$. After prolonged time $\mathrm{Ir} / \mathrm{ZrO}_{2}$ was able to transform 2-methoxycyclohexanone to cyclohexanol and also substantial yield of cyclohexane (14\% yield) was formed (Fig. 6b, Table 6). This intermediate, 2-methoxycyclohexanonone was, however, only partially transformed to cyclohexane (Fig. 6b).

As a conclusion it can be stated that $\mathrm{Ir} / \mathrm{ZrO}_{2}$ was more active than $\mathrm{Ni} / \mathrm{ZrO}_{2}$ to produce fully deoxygenation product cyclohexane. The drawback with this catalyst was the low liquid phase mass balance closure due to high hydrogenolysis activity of Ir forming also large amounts of the gaseous products.

\section{Vanillin HDO}

Hydrodeoxygenation of vanillin was performed using $10 \mathrm{wt} \% \mathrm{Ni} / \mathrm{ZrO}_{2}$ and $3 \mathrm{wt} \%$ $\mathrm{Ir} / \mathrm{ZrO}_{2}$ at $100{ }^{\circ} \mathrm{C}$ and 30 bar total pressure in the presence of hydrogen and water used as a solvent (Fig. 7). Vanillin concentration decreased during the initial heating probably due to strong adsorption of it on the catalyst surface similar to observations of Santos et al. [5]. Initially the transformation rate of vanillin between 1 and $30 \mathrm{~min}$ of the reaction time was $0.0035 \mathrm{~mol} / \mathrm{min} / \mathrm{g}_{\mathrm{Ni}}$ for $\mathrm{Ni} / \mathrm{ZrO}_{2}$ being almost the same whereas for $\mathrm{Ir} / \mathrm{ZrO}_{2}$ it was $\left(0.003 \mathrm{~mol} / \mathrm{min} / \mathrm{g}_{\mathrm{Ir}}\right)$. Both of these catalysts exhibited Ni particles of rather small sizes (Table 2) and the differences in their performance were minor. The catalytic activity in vanillin transformation was, however, retarded substantially over $\mathrm{Ni} / \mathrm{ZrO}_{2}$ after 60 min, whereas $\mathrm{Ir} / \mathrm{ZrO}_{2}$ was more active. The former catalyst has more Lewis acid sites and also small amounts of Bronsted acid sites (Table 3), which can cause catalyst deactivation. Vanillin conversions were nearly the same for $10 \mathrm{wt} \% \mathrm{Ni} / \mathrm{ZrO}_{2}$ and $\mathrm{Ir} / \mathrm{ZrO}_{2}$ being $94 \%$ and $99 \%$, respectively after $4 \mathrm{~h}$. GCLPA was the best over $10 \mathrm{wt} \% \mathrm{Ni} / \mathrm{ZrO}_{2}$ being $92 \%$. Over $\mathrm{Ir} / \mathrm{ZrO}_{2}$ the GCLPA was $78 \%$ indicating higher hydrogenolysis activity of Ir [20].

Using $10 \mathrm{wt} \% \mathrm{Ni} / \mathrm{ZrO}_{2}$ catalyst, the main product was vanillin alcohol with the yield of $86 \%$ after four hours of the reaction unconverted vanillin was also present (Table 6, Fig. 7a). No other products were seen in HPLC, such as p-cresol or $p$-creosol, due to low activity (mild acidity) in hydrodeoxygenation. Analogously to nickel the main product over $\mathrm{Ir} / \mathrm{ZrO}_{2}$ was also vanillyl alcohol with the yield of $77 \%$ (Table 6, Fig. 7b). It can be concluded that these catalysts did not facilitate deoxygenation of vanillin under the studied reaction conditions. Vanillin HDO requires much more severe conditions. In particular experiments at $300{ }^{\circ} \mathrm{C}$ under 50 bar of hydrogen utilization of $\mathrm{Ni} / \mathrm{SiO}_{2}-\mathrm{ZrO}_{2}$ gave at $83 \%$ conversion $65 \%$ selectivity to methylcyclohexane [4]. Typically, partial deoxygenation of vanillin in water as a solvent was obtained forming $p$-creosol as the main product under 30 bar at $100{ }^{\circ} \mathrm{C}$ over $\mathrm{Pd} / \mathrm{C}$ [5]. This comparison shows that $\mathrm{Pd}$ has electronic properties facilitating formation of $p$-creosol under mild conditions, whereas $\mathrm{Ni}$ as a transition metal is less active. 

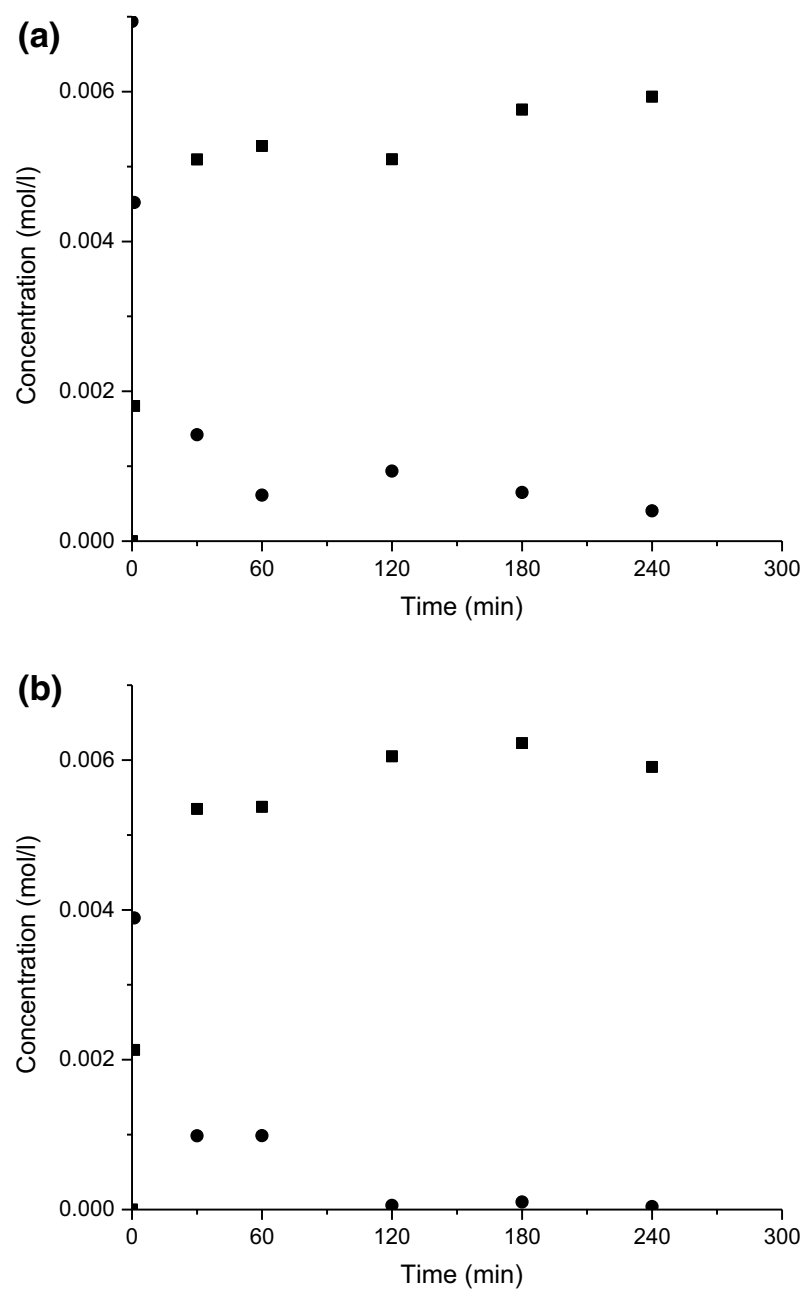

Fig. 7 Kinetics in $\mathrm{HDO}$ of vanillin over a $\mathrm{NiZrO}_{2}$ and $\mathbf{b ~} \mathrm{Ir} / \mathrm{ZrO}_{2}$ catalysts. Conditions: $250{ }^{\circ} \mathrm{C}$, total pressure $30 \mathrm{bar}$, initial vanillin concentration $0.008 \mathrm{~mol} / \mathrm{l}$, solvent water, catalyst mass $50 \mathrm{mg}$. Notation: vanillin (filled circle) and vanillyl alcohol (filled square)

\section{Conclusions}

A comparative investigation of isoeugenol, guaiacol and vanillin hydrodeoxygenation was performed using $\mathrm{Ni}$ and $\mathrm{Ir}$ supported $\mathrm{ZrO}_{2}$ catalysts prepared by the incipient wetness method. Both catalysts exhibited Lewis acidity, whereas $\mathrm{Ni} / \mathrm{ZrO}_{2}$ contained also weak Brønsted acid sites.

The deoxygenation efficiency of $\mathrm{Ni} / \mathrm{ZrO}_{2}$ was low in isoeugenol transformation at $150{ }^{\circ} \mathrm{C}$ under $30 \mathrm{bar}$, increasing with temperature elevation. Analogous results were found for $\mathrm{Ir} / \mathrm{ZrO}_{2}$. The drawback with these catalysts in isoeugenol transformation was the low liquid phase mass balance closure due to formation of large amounts 
of gas phase products in the liquid phase. In guaiacol $\mathrm{HDO}$ over $3 \mathrm{wt} \% \mathrm{Ir} / \mathrm{ZrO}$, the maximum yield of cyclohexane at $250{ }^{\circ} \mathrm{C}$ under 30 bar is $14 \%$. The main product was cyclohexanol indicating that this catalyst facilitated only partial deoxygenation, which can be related to low acidity. $\mathrm{Ni} / \mathrm{ZrO}_{2}$ also gave cyclohexanol as the main product.

Vanillin transformation in water at $100{ }^{\circ} \mathrm{C}$ under 30 bar resulted in formation of vanillyl alcohol as the main product indicating that $\mathrm{Ir}$ and $\mathrm{Ni}$ supported $\mathrm{ZrO}_{2}$ catalysts at these conditions provide only partial HDO of vanillin.

Acknowledgements Open access funding provided by Abo Akademi University (ABO). The authors acknowledge the financial support provided by Neste Corporation.

Open Access This article is distributed under the terms of the Creative Commons Attribution 4.0 International License (http://creativecommons.org/licenses/by/4.0/), which permits unrestricted use, distribution, and reproduction in any medium, provided you give appropriate credit to the original author(s) and the source, provide a link to the Creative Commons license, and indicate if changes were made.

\section{References}

1. Mäki-Arvela P, Murzin DYu (2017) Hydrodeoxygenation of lignin-derived phenols: from fundamental studies towards industrial applications. Catalysts 7(9):1-40

2. Boscagli C, Raffelt K, Zevaco TA, Olbrich W, Otto TN, Sauer J, Grundwaldt JD (2015) Mild hydrotreatment of the light fraction of fast-pyrolysis oil produced from straw over nickel-based catalysts. Biomass Bioenergy 83:525-538

3. Oh S, Choi HS, Choi IG, Choi JW (2017) Evaluation of hydrodeoxygenation reactivity of pyrolysis bio-oil with various Ni-based catalysts for improvement of fuel properties. RSC Adv 7:15116-15126

4. Zhang X, Tang W, Zhang Q, Wang T, Ma L (2017) Hydrocarbons production from lignin-derived phenolic compounds over $\mathrm{Ni} / \mathrm{SiO}_{2}$ catalyst. Energy Proc 105:518-523

5. Santos JL, Alda-Onggar M, Fedorov V, Peurla M, Eränen K, Mäki-Arvela P, Centeno MÁ, Murzin DYu (2018) Hydrodeoxygenation of vanillin over carbon supported metal catalysts. Appl Catal A 561:137-149

6. He L, Qin Y, Lou H, Chen P (2015) Highly dispersed molybdenum carbide nanoparticles supported on activated carbon as an efficient catalyst for the hydrodeoxygenation of vanillin. RSC Adv 5:43141-43147

7. Bomont L, Alda-Onggar M, Fedorov V, Aho A, Peltonen J, Eränen K, Peurla M, Kumar N, Wärnå J, Russo V, Mäki-Arvela P, Grenman H, Lindblad M, Murzin DYu (2018) Production of cycloalkanes in hydrodeoxygenation of isoeugenol over Pt- and Ir- modified bifunctional catalysts. Eur J Inorg Chem 24:2841-2854

8. Gonzales C, Marin P, Diaz FV, Ordonez S (2016) Gas-phase hydrodeoxygenation of benzaldehyde, benzyl alcohol, phenyl acetate and anisole over precious metal catalysts. Ind Eng Chem Res 55:2319-2327

9. Teles CA, Rabelo-Neto RC, Jacobs G, Davis BH (2017) Resasco DE, Noronha FB, Hydrodeoxygenation of phenol over zirconia-supported catalysts: the effect of metal type on reaction mechanism and catalyst deactivation. ChemCatChem 9:2850-2863

10. Mortensen PM, Grunwaldt JD, Jensen PA, Jensen AD (2013) Screening of catalysts for hydrodeoxygenation of phenol as a model compounds for bio-oil. ACS Catal 3:1774-1785

11. Chen CJ, Bhan A (2017) $\mathrm{Mo}_{2} \mathrm{C}$ modification by $\mathrm{CO}_{2}, \mathrm{H}_{2} \mathrm{O}$, and $\mathrm{O}_{2}$ : effect of oxygen content and oxygen source on rates and selectivity of m-cresol hydrodeoxygenation. ACS Catal 7:1113-1122

12. Sulman A, Mäki-Arvela P, Bomont L, Fedorov V, Alda-Onggar M, Smeds A, Hemming J, Russo V, Wärnå J, Käldström M, Murzin DYu (2018) Vanillin hydrodeoxygenation: kinetic modelling and solvent effect. Catal Lett 148:2856-2868 
13. Goncalves VOO, de Souza PM, Cabioc'h T, da Silva VT, Noronha FB, Richard F (2017) Hydrodeoxygenation of $\mathrm{m}$-cresol over nickel and nickel phosphide based catalysts. Influence of the nature of the active phase and the support. Appl Catal B 219:619-628

14. Liu X, Jia W, Xu G, Zhang Y, Fu Y (2017) Selective hydrodeoxygenaiton of lignin-derived phenols to cyclohexanols over Co-based catalsyts. ACS Sust Chem Eng 5:8594-8601

15. Zhang X, Zhang Q, Wang T, Ma L, Yu Y, Chen L (2013) Hydrodeoxygenation of lignin-derived phenolic compounds to hydrocarbons over $\mathrm{Ni} / \mathrm{SiO}_{2}-\mathrm{ZrO}_{2}$ catalysts. Biores Technol 134:73-80

16. Lee CR, Yoon JS, Suh YW, Choi JW, Ha JM, Suh DJ, Park YK (2012) Catalytic roles of metals and supports on hydrodeoxygenation of lignin monomer guaiacol. Catal Commun 17:54-58

17. Mortensen PM, Gardini D, de Carvalho HWP, Damsgaard CD, Grunwaldt JD, Jensen PA, Wagner JK, Jensen AD (2014) Stability and resistance of nickel catalysts for hydrodeoxygenation: carbon deposition and effects of sulfur, potassium, and chlorine in the feed. Catal Sci Technol 4:3672-3686

18. Lu M, Du H, Wei B, Zhu J, Li M, Shan Y, Shen J, Song C (2017) Hydrodeoxygenation of guaiacol on $\mathrm{Ru}$ catalysts: influence of $\mathrm{TiO}_{2}-\mathrm{ZrO}_{2}$ composite oxide supports. Ind Eng Chem Res 56:12070-12079

19. Gutierrez A, Kaila RK, Honkela ML, Slioor R, Krause AOI (2009) Hydrodeoxygenation of guaiacol on noble metal catalysts. Catal Today 147(3-4):239-246

20. Chen K, Mori K, Watanabe H, Nakagawa Y, Tomishige K (2012) C-O bond hydrogenolysis of cyclic ethers with $\mathrm{OH}$ groups over rhenium-modified supported iridium catalysts. J Catal 294:171-183

21. Sullivan RJ, Latifi E, Chung BKM, Soldatov DV, Schlaf M (2014) Hydrodeoxygenation of 2,5-hexanedione and 2,5-dimethylfuran by water, air and acid-stable homogeneous ruthenium and iridium catalysts. ACS Catal 4:4116-4128

22. Bykova MV, Zavarukhin SG, Trusov LI, Yakovlev VA (2013) Guaiacol hydrodeoxygenation kinetics with catalyst deactivation taken into consideration. Kinet Catal 54:40-48

23. Roldugina EA, Naranov ERE, Maximov AL, Karakhanov EA (2018) Hydrodeoxygenation of guaiacol as a model compoubnd of bio-oil in methanol over mesoporous noble metal catalysts. Appl Catal A. https://doi.org/10.1016/j.apcata.2018.01.2018

24. Liu S, Dutta S, Zheng W, Gould NS, Cheng Z, Xu B, Saha B, Vlachos DG (2017) Catalytic hydrodeoxygenation of high carbon furylmethanes to renewable jet-fuel ranged alkanes over a rheniummodified iridium catalyst. ChemSusChem 10:3225-3234

25. Ohta H, Kobayashi H, Hara K, Fukuoka A (2011) Hydrodeoxygenation of phenols as lignin models under acid-free conditions with carbon-supported platinum catalysts. ChemComm 47:12209-12211

26. Alda-Onggar M, Mäki-Arvela P, Eränen K, Aho A, Hemming J, Paturi P, Peurla M, Lindblad M, Simakova IL, Murzin DYu (2018) Hydrodeoxygenation of isoeugenolover alumina supported Ir-, Pt- and Re catalysts. ASC Sust. Chem. Eng. https://doi.org/10.1021/acssuschemeng.8b03035

27. Santillan-Jiminez E, Perdu M, Pace R, Morgan T, Crocker M (2015) Activated carbon, carbon nanofiber and carbon nanotube supported molybdenum carbide catalysts for the hydrodeoxygenation of guaiacol. Catalyst 5:424-441

28. Nabgan W, Abdullah TAT, Mat R, Nabgan B, Gambo Y, Johari A (2016) Evaluation of reaction parameters of the phenol steam reforming over $\mathrm{Ni} / \mathrm{Co}$ on $\mathrm{ZrO}_{2}$ using the full factorial experimental design. Appl Sci 6(223):1-21

29. Emeis CA (1993) Determination of integrated molar extinction coefficients for infrared absorption bands of pyridine adsorbed on solid acid catalysts. J Catal 141:335-347

30. Kumar VV, Naresh G, Sudhakar M, Anjaneyulu C, Bhargava SK, Tardio J, Reddy VK, Padmasri AH, Venugopal A (2016) An investigation on the influence of support type for Ni catalyzed vapour phase hydrogenation of aqueous levulinic acid to $\gamma$-valerolactone. RSC Adv 6:9872-9879

31. Rabee AIM, Mekhemer GAH, Osatiashtiani A, Isaacs MA, Lee AF, Wilson K, Zaki MI (2017) Acidity-reactivity relationships in catalytic esterification over ammonium sulfate-derived sulfated zirconia. Catalysts 7(204):1-16

32. Bjelić A, Grilc M, Likozar B (2018) Catalytic hydrogenation and hydrodeoxygenation of ligninderived model compound eugenol over $\mathrm{Ru} / \mathrm{C}$ : intrinsic microkinetics and transport phenomena. Chem Eng J 333:240-259

33. Barin I (1989) Thermochemical data of pure substances. VCH, Weinheim

34. Benzon SW (1968) Thermochemical kinetics: methods for estimation of thermochemical data rate parameters. John Wiley \& Sons, Inc., New York 